\title{
Identifikasi Risiko Proyek Konstruksi Gedung Di Provinsi Aceh
}

\author{
Kemala Hayati ${ }^{\mathrm{a}}$, Aldina Fatimah ${ }^{\mathrm{a}}$, Badrul Akmal ${ }^{\mathrm{a} *}$ \\ Program Studi Teknik Sipil, Fakultas Teknik, Universitas Muhammadiyah Aceh
}

Riwayat Artikel

Diserahkan

7 Juni 2021

Direvisi

10 Agustus 2021

Diterima

30 Agustus 2021

${ }^{*}$ Penulis korespondensi

aldina.fatimah@unmuha.ac.id

\begin{abstract}
Abstrak
Risiko dalam proyek konstruksi merupakan suatu potensi kejadian yang dapat menyebabkan kerugian yang muncul dalam satu periode waktu. Penelitian ini bertujuan mengidentifikasi risikorisiko yang dapat terjadi dalam proyek konstruksi gedung. Pengolahan data dalam penelitian menggunakan analisis deskriptif serta probability impact matrix dalam manajemen risiko. Berdasarkan analisis risiko dengan menggunakan probability impact matrix, diketahui bahwa dua risiko tertinggi, yaitu "tidak menghitung mutual check nol dengan akurat saat hendak melakukan pekerjaan" serta "tidak segera memperbaiki kecatatan pada material". Dari risiko tersebut, perlu tindakan preventif supaya risiko tersebut dapat dihindari. Suatu pedoman preventif dapat bermanfaat untuk membantu penyedia jasa dalam menangani risiko yang terjadi dalam pelaksanaan proyek konstruksi serta membantu penyedia jasa mencegah klaim berkembang menjadi dispute. Tindakan pencegahan yang dapat dilakukan dari risiko tersebut adalah dengan mencari sumber daya manusia yang berkualitas, memperketat pengawasan di lapangan, membuat pelatihan bagi pekerja serta pengelolaan manajemen yang baik.
\end{abstract}

Kata-kata kunci: Manajemen Risiko, Penyebab Risiko, Tindakan Preventif

\begin{abstract}
A construction project has some risks that likely happen and cause financial loss in a certain time. This research is aimed to identify possible risks in building construction. It applied descriptive analysis and probability impact matrix to manage the risks. Based on the risk analysis by using probability impact matrix, there were two possible risks with the highest value, i.e. "Inaccurate zero mutual check", and "The material defects are not immediately repaired". According to the aforementioned risks, some prevention should be undertaken. A guideline on preventive measure is useful to help the contractor to manage the possible risks in construction project, and prevent a dispute. Some prevention that can be solution of the risks are finding the qualified human resources, tighten the supervision, conduct development and training for the staffs, and provide good management.
\end{abstract}

Keywords: Risk Management, Causes of Risk, Preventive Action

(c) 2019 Penerbit LP3M UMY. All rights reserved

\section{PENDAHULUAN}

Bangunan gedung erat kaitannya dengan pengembangan suatu kota. Sulitnya pengadaan lahan dan juga harga lahan yang sangat tinggi mempunyai dampak yang signifikan terhadap meningkatnya pemilihan bangunan gedung. Proyek konstruksi gedung merupakan salah satu jasa konstruksi yang banyak dipenuhi risiko yang bervariasi selama tahap pelaksanaan.

Suatu proyek dapat dikatakan berhasil apabila dalam pelaksanaan proyek tersebut memenuhi tiga kriteria yaitu, tepat biaya, tepat mutu dan tepat waktu. Kesuksesan proyek konstruksi sangat tergantung juga dari kemampuan manajer proyek dalam mengelola risiko yang terjadi. Manajemen risiko sangat penting bagi kelangsungan suatu usaha atau kegiatan. Manajemen risiko merupakan pendekatan yang efektif untuk menangani risiko pada proyek konstruksi dengan cara mengidentifikasi sumber risiko dan ketidakpastian, menetapkan pengaruhnya dan mengembangkan respon yang tepat. Tujuan dari manajemen risiko proyek adalah untuk meningkatkan probabilitas dan dampak positif terhadap kejadian dan mengurangi probabilitas dan dampak kejadian yang merugikan sasaran proyek (Project Management Institute, 2013)

Sayangnya, pada setiap kegiatan usaha jasa konstruksi akan selalu muncul dua hal yang berdampingan, dua hal tersebut yaitu adanya peluang memperoleh keuntungan dan risiko mengalami kerugian. Tidak sedikit usaha jasa konstruksi yang mengalami kegagalan maupun kerugian dikarenakan ketidak tepatan dalam mengambil keputusan dalam menangani risiko. Identifikasi risiko adalah usaha untuk menemukan atau mengetahui risiko-risiko yang mungkin timbul dalam kegiatan yang dilakukan oleh perusahaan atau perorangan. Tujuannya adalah untuk melakukan formulasi dan kategorisasi risiko dengan komponen penyebab terjadinya dan dampak dari risiko tersebut. Metode yang dapat digunakan bermacammacam, salah satunya adalah dengan membuat checklist, daftar risiko ini dapat dikembangkan berdasarkan informasi yang telah dikumpulkan dari proyek lampau (Loosemore, dkk., 2006; Zhang dkk, 2016)

Project Management Institute (2013) menyebutkan analisa risiko merupakan proses mencari informasi/deskripsi lebih spesifik terhadap risiko yang telah diidentifikasi meliputi kuantifikasi risiko dalam 
probabilitas, penyebab terjadinya dan keterkaitan risiko. Dampak risiko yang berpotensi mempengaruhi kualitas konstruksi seperti waktu, harga dan mutu pekerjaan perlu dikaji untuk dapat merencanakan respon risiko. Perencanaan respon risiko adalah suatu proses untuk mengembangkan pilihan dan menentukan tindakan untuk meningkatkan kesempatan atau mengurangi ancaman terhadap tujuan proyek. Preventif atau pencegahan merupakan salah satu pilihan dari respon risiko. Pedoman preventif ini dapat diterapkan pada masa perencanaan hingga pelaksanaan, dimana hasil identifikasi risiko-risiko yang dapat mengganggu keberlangsungan atau menggagalkan proyek, dapat terlebih dahulu ditentukan tindakan preventifnya dan dapat diterapkan sehingga risiko tersebut tidak terjadi atau memiliki efek kecil

Berdasarkan latar belakang dan permasalahan tersebut maka dilakukan penelitian mengenai identifikasi manajemen risiko proyek konstruksi gedung, dan bagaimana tindakan penangganan yang harus dilakukan terhadap faktor risiko tersebut serta dapat memberi masukan dan saran ke instansi terkait. Ruang lingkup penelitian ini dilakukan pada perusahaan jasa konstruksi di Provinsi Aceh. Langkah pertama yang dilakukan dalam penelitian ini yaitu menentukan variabel-variabel risiko yang kemungkinan berpengaruh terhadap mutu, biaya, dan waktu. Selanjutnya menyediakan kuisioner untuk disebarkan kepada responden. Responden dalam penelitian ini yaitu pihak kontraktor yang sudah berpengalaman di bidang penyedia jasa konstruksi gedung.

\section{METODE PENELITIAN}

\subsection{Objek dan Lokasi Penelitian}

Objek yang diidentifikasi adalah risiko pada proyek konstruksi gedung yang terletak di Kota Banda Aceh dan Aceh Besar.

\subsection{Pengolahan Data}

Data penelitian diperoleh dari pengisian kuisioner ke responden (kontraktor) sebanyak 63 orang yang dilakukan di Kota Banda Aceh dan Aceh Besar dengan variabel ang dianalisis yaitu mutu, biaya dan waktu. Hasil survey kuisioner kemudian diolah secara manual dengan bantuan Microsoft Excel dengan pemberian kode (X) berupa angka (1,2,3, dan seterusnya) yang sudah ditentukan. Hal ini bertujuan untuk mempermudah proses analisa data. Kode tiap-tiap risiko dapat dilihat pada Tabel 1.

Proses pengolahan data mencakup uji validitas untuk mengetahui ketepatan instrumen penelitian sebelum data diiterpretasikan. Setelah uji validitas dilakukan, instrumen yang digunakan selanjutnya adalah yang telah memenuhi kriteria valid. Analisa data ini menggunakan metode statistik yaitu Probability and Impact Matrix, serta Analisis Deskriptif dan Homogenitas.

Tabel 1 Kode Faktor Risiko

\begin{tabular}{cc}
\hline Kode & Faktor Risiko / Variabel \\
\hline & Mutu \\
\hline X1 & Tidak segera memperbaiki kecacatan material \\
X2 & Dimensi material tidak sesuai \\
X3 & Pekerja sering lembur
\end{tabular}

\begin{tabular}{|c|c|}
\hline $\begin{array}{l}X 4 \\
X 5\end{array}$ & $\begin{array}{c}\text { Pekerja sering tidak tepat waktu masuk kerja } \\
\text { Pekerja tidak terampil }\end{array}$ \\
\hline $\mathrm{X} 6$ & $\begin{array}{c}\text { Melakukan pengecatan pada dinding sebelum } \\
\text { plasteran kering. }\end{array}$ \\
\hline $\mathrm{X} 7$ & $\begin{array}{c}\text { Tidak menggunakan vibrator pada saat } \\
\text { pengecoraan }\end{array}$ \\
\hline $\mathrm{X} 8$ & $\begin{array}{l}\text { Tidak melakukan pemeliharaan pada beton } \\
\text { secara berkala }\end{array}$ \\
\hline X9 & $\begin{array}{c}\text { Tidak mencatat kelengkapan material yang ada di } \\
\text { lapangan }\end{array}$ \\
\hline $\mathrm{X} 10$ & Harga material naik di pasaran \\
\hline $\mathrm{X} 11$ & Dimensi material yang dibeli tidak sesuai \\
\hline $\mathrm{X} 12$ & Barang yang didatangkan dari lokasi yang jauh \\
\hline & Biaya \\
\hline $\mathrm{X} 13$ & $\begin{array}{l}\text { Tidak melakukan Mutual Check } 0 \text { saat hendak } \\
\text { memulai pekerjaan }\end{array}$ \\
\hline $\mathrm{X} 14$ & $\begin{array}{c}\text { Pemotongan anggaran apabila ada pengurangan } \\
\text { volume pekerjaan }\end{array}$ \\
\hline $\mathrm{X} 15$ & $\begin{array}{c}\text { Pekerjaan tidak dapat dilakukan sesuai gambar } \\
\text { kerja }\end{array}$ \\
\hline $\mathrm{X} 16$ & Tidak menggunakan excafator saat menggali \\
\hline \multirow[t]{2}{*}{$\mathrm{X} 17$} & Tidak membandingkan harga supplier \\
\hline & Waktu \\
\hline $\mathrm{X} 18$ & $\begin{array}{c}\text { Tidak memberi fasilitas yang memadai terhadap } \\
\text { pekerja }\end{array}$ \\
\hline $\mathrm{X} 19$ & $\begin{array}{c}\text { Terjadinya perubahan pekerjaan yang berulang } \\
\text { akibat kekeliruan }\end{array}$ \\
\hline $\mathrm{X} 20$ & $\begin{array}{c}\text { Tidak Membuat PDM (Precedence Diagraming } \\
\text { Methode) }\end{array}$ \\
\hline $\mathrm{X} 21$ & Tidak membuat rencana kerja mingguan \\
\hline $\mathrm{X} 22$ & $\begin{array}{l}\text { Tidak menerapkan kerja lembur dan pembagian } \\
\text { shift kerja untuk percepatan proyek }\end{array}$ \\
\hline
\end{tabular}

\subsection{Probability and Impact Matrix}

Probability and Impact Matrix (PIM) adalah salah satu metode untuk menganalisis risiko secara kualitatif kemungkinan suatu risiko muncul. Penilaian risiko dilakukan berdasarkan peluang probabilitas dan konsekuensinya/dampaknya (Sufa'atin, 2017; Sun, dkk., 2008). Hal tersebut dilakukan untuk memberikan penilaian terhadap probabilitas dari setiap risiko dan dampak yang ditimbulkan adalah dengan membuat skala. Skala yang digunakan adalah skala Likert. Skala likert adalah skala yang umum dipakai dalam survey untuk mengukur sikap, pendapat, dan persepsi subyek terhadap suatu obyek (Dita, dkk., 2017; Ratnaningsih, dkk., 2018). Skala tersebut dibagi ke dalam lima tingkatan yaitu VHI (Very High) sangat tinggi, Med (Medium) sedang, LO (Low) rendah, dan VLO (Very Low) sangat rendah. Jika nilai risiko > 14 maka risiko masuk tingkat tinggi $(\mathrm{H})$, jika nilai risiko 8-14 masuk tingkat sedang $(\mathrm{M})$, sedangkan jika nilai risiko < 8 maka masuk tingkatan rendah (L).

Dari hasil kuesioner, dilakukan analisa deskriptif untuk didapatkan nilai rata-rata frekuensi dan nilai ratarata dampak. Kemudian dilakukan perkalian antara nilai rata-rata frekuensi dengan nilai rata-rata dampak, sehingga 
didapat nilai risiko untuk masing-masing variabel. Berikut ini adalah rumus untuk menghitung nilai risiko.

$R=F \cdot D$

dimana $R$ adalah risiko, $F$ adalah frekuensi penilaian, dan $D$ adalah dampak yang diakibatkan.

Penilaian risiko dilakukan berdasarkan peluang atau probabilitas dan konsekuensinya atau dampaknya. Hal tersebut dilakukan untuk memberikan penilaian terhadap probabilitas dari setiap risiko dan dampak. Langkah berikutnya yaitu menghitung tingkat kepentingan risikonya setelah skala probabilitas, dampak dan tingkat kepentingan/level risiko telah diketahui. Langkah selanjutnya memetakan level risiko ke dalam matriks. Berdasarkan matriks, level risiko yang berdampak negatif dan dapat menimbulkan ancaman dapat diketahui. Dari penilaian risiko, dicari nilai rerata (mean) masing-masing faktornya, lalu diurutkan berdasarkan peringkat nilai rataratanya untuk mengetahui faktor dominan dari risiko tersebut.

\section{HASIL DAN PEMBAHASAN}

\subsection{Analisa Deskriptif}

Berdasarkan hasil dari analisa deskriptif untuk variabel X yang ditampilkan dalam Tabel 2, didapatkan bahwa mean tertinggi terletak pada variabel X13 dengan nilai mean 4,4242. X13 menunjukkan peristiwa "tidak menghitung mutual check nol dengan akurat saat hendak melakukan pekerjaan”. Hal tersebut menunjukkan bahwa mayoritas responden menyatakan bahwa X13 memiliki frekuensi dan dampak yang tinggi terhadap terjadinya risiko dalam proyek konstruksi.

\subsection{Analisa Level Risiko}

Berdasarkan Tabel 3, didapatkan risiko mana saja yang termasuk kategori risiko tinggi, sedang, dan rendah. Untuk faktor mutu, 7 dari 9 variabel mempunyai tingkat risiko sedang dan 2 variabel mempunyai risiko rendah. Untuk faktor biaya dari 7 varibel 6 dintaranya mempunyai risiko sedang dan 1 variabel mempunyai risiko rendah. Sedangkan untuk faktor waktu dari 5 variabel 4 diantaranya mempunyai risiko sedang dan 1 variabel mempunyai risiko rendah. Dari keseluruhan variabel mutu, biaya dan waktu dapat disimpulkan bahwa tidak ada variabel yang masuk tingkat risiko tinggi (high risk) karena nilai risiko yang didapat tidak lebih besar dari 14 .

Tabel 3 menunjukkan bahwa indikator mutu memiliki nilai tertinggi pada variabel X3 "pekerja sering lembur” dengan nilai 12,98 dengan level sedang (medium). Faktor tersebut yang paling dominan dikarenakan kontrakor mengejar keterlambatan jadwal, mempercepat penyelesaian proyek, mengatasi peningkatan dimensi atau volume akibat adanya perubahan desain, serta mengatasi kekurangan pekerja. Dampak dari pekerja sering lembur antara lain menurunya produktifitas akibat kelelahan pada pekerja, sehingga ditakutkan akan berdampak pada mutu pekerjaan dan mengakibatkan peningkatan biaya upah tenaga kerja. Tindakan preventif yang dapat dilakukan dari variabel X3 adalah dengan mengikuti jadwal tiap-tiap tahapan pekerjaan yang sudah direncanakan dari kurva S atau PDM (Precedence Diagraming Methode).
Tabel 2 Nilai Parameter Statistik Tiap Variabel

\begin{tabular}{cccccc}
\hline Variabel & $\mathrm{N}$ & Min & Max & Mean & Std. Deviation \\
\hline & \multicolumn{5}{c}{ Mutu } \\
\hline X1 & 33 & 2 & 5 & 4.2424 & 0.61392 \\
X2 & 33 & 4 & 5 & 4.2424 & 0.43519 \\
X3 & 33 & 3 & 5 & 3.9697 & 0.39409 \\
X4 & 33 & 3 & 5 & 4.0909 & 0.52223 \\
X5 & 33 & 2 & 5 & 4.0909 & 0.723 \\
X6 & 33 & 3 & 5 & 4.1212 & 0.64988 \\
X7 & 33 & 3 & 5 & 4.1212 & 0.5453 \\
X8 & 33 & 2 & 5 & 3.3636 & 0.85944 \\
X9 & 33 & 3 & 4 & 3.5152 & 0.50752 \\
X10 & 33 & 2 & 5 & 4.0303 & 0.72822 \\
X11 & 33 & 3 & 5 & 3.6667 & 0.59512 \\
X12 & 33 & 4 & 5 & 4.1515 & 0.36411 \\
\hline \multicolumn{5}{c}{ Biaya } & \\
\hline X13 & 33 & 3 & 5 & 4.4242 & 0.66287 \\
X14 & 33 & 2 & 5 & 3.4242 & 0.8303 \\
X15 & 33 & 4 & 5 & 4.0303 & 0.17408 \\
X16 & 33 & 4 & 5 & 4.2121 & 0.41515 \\
X17 & 33 & 3 & 5 & 4.0303 & 0.46669 \\
\hline \multicolumn{5}{c}{ Waktu } \\
\hline X18 & 33 & 4 & 5 & 4.1515 & 0.36411 \\
X19 & 33 & 3 & 5 & 4.1212 & 0.41515 \\
X20 & 33 & 1 & 4 & 3.3333 & 0.88976 \\
X21 & 33 & 3 & 4 & 3.8182 & 0.39167 \\
X22 & 33 & 3 & 5 & 3.7576 & 0.50189 \\
\hline
\end{tabular}

Tabel 3 Hasil Analisis Level Risiko

\begin{tabular}{ccccc}
\hline Variabel & $\begin{array}{c}\text { Rata } \\
\text { rata } \\
\text { Frekuensi } \\
(F)\end{array}$ & $\begin{array}{c}\text { Rata - rata } \\
\text { Dampak } \\
(D)\end{array}$ & $\begin{array}{c}\text { Risiko } \\
(F \times D)\end{array}$ & $\begin{array}{c}\text { Level } \\
\text { Risiko }\end{array}$ \\
\hline \multicolumn{5}{c}{ X1 - X9 Faktor Mutu } \\
\hline X1 & 1,879 & 3,576 & 7,458 & Rendah \\
X2 & 2,485 & 3,970 & 9,713 & Sedang \\
X3 & 3,455 & 3,909 & 12,981 & Sedang \\
X4 & 3,182 & 3,758 & 9,835 & Sedang \\
X5 & 2,576 & 3,576 & 9,835 & Sedang \\
X6 & 2,394 & 3,909 & 6,747 & Rendah \\
X7 & 2,636 & 3,818 & 10,306 & Sedang \\
X8 & 2,970 & 2,818 & 9,359 & Sedang \\
X9 & 2,545 & 3,152 & 8,022 & Sedang \\
\hline \multicolumn{5}{c}{ X10 X17 Faktor Biaya } \\
\hline X10 & 3,485 & 3,722 & 8,022 & Sedang \\
X11 & 3,030 & 3,000 & 12,971 & Sedang \\
X12 & 2,394 & 3,889 & 9,091 & Sedang \\
X13 & 1,606 & 3,389 & 9,310 & Sedang \\
X14 & 2,788 & 3,167 & 5,443 & Rendah \\
X15 & 3,485 & 3,167 & 8,828 & Sedang \\
X16 & 1,879 & 4,222 & 11,035 & Sedang \\
X17 & 2,182 & 4,000 & 7,933 & Rendah \\
\hline \multicolumn{5}{c}{ X18 X22 Faktor Waktu } \\
\hline X18 & 2,152 & 3,833 & 8,247 & Sedang \\
X19 & 2,061 & 3,333 & 6,869 & Rendah \\
X20 & 2,667 & 3,056 & 8,148 & Sedang \\
X21 & 2,455 & 3,722 & 9,136 & Sedang \\
X22 & 2,697 & 3,222 & 8,690 & Sedang \\
\hline \multicolumn{5}{c}{}
\end{tabular}

Untuk indikator biaya, nilai risiko yang tertinggi yaitu pada variabel X11 "Pekerja tidak terampil" dengan nilai 12,971 dengan level risiko sedang (medium). Faktor tersebut menjadi yang paling dominan karena dalam proses pengadaan pekerja sering sekali tidak dilakukan rekrut tenaga kerja secara prosedur seperti menunjukan sertifikat keahlian yang dikuasai masing-masing pekerja, hal ini menunjukan susahnya mencari sumber daya manusia (SDM) yang berkompeten. Dampak dari pekerja tidak terampil, antara lain terjadi kesalahan pada pekerjaan dilapangan seperti salah pembacaan gambar, 
dimensi, sehingga pekerjaan akan berulang (rework), dan ditakutkan akan berdampak pada biaya pekerjaan yang bertambah dari perkiraan awal sehingga akan berpengaruh pada waktu. Tindakan preventif yang dapat dilakukan dari variabel X11 adalah dengan memanfaatkan tim proyek yang ada dan diberikan training serta buku pelatihan agar lebih memahami tiap tahapan pekerjaan yang dilakukan dan memperbanyak komunikasi dengan tim proyek agar dapat diarahkan dengan baik.

Untuk indikator waktu, diperoleh nilai risiko tertinggi pada variabel X21 "Tidak membuat rencana kerja mingguan" dengan nilai 9,136 dengan level risiko sedang (medium). Faktor X21 yang paling dominan pada indikator waktu dikarenakan penyedia jasa tidak memperkerjakan tenaga teknis yang berkompeten pada bidang manajemen penjadwalan proyek sehingga waktu pekerjaan proyek tidak dapat dikontrol dengan baik. Dampak dari X21 adalah tidak dibuatnya rencana kerja mingguan antara lain sehingga berpengaruh pada waktu penyelesaian proyek konstruksi. Karena tidak ada pedoman penjadwalan yang bisa diikuti, penyedia jasa tidak dapat mengetahui apakah pekerjaan tersebut mengalami keterlambatan atau kecepatan dari rencana serta pekerjaan apa saja yang termasuk jalur kritis. Tindakan preventif yang dapat dilakukan dari variabel X21 adalah dengan membuat satu unit sistem informasi manajemen untuk membuat rencana kerja mingguan, memantau dan menganalisa apa yang terjadi dan tindakan apa yang perlu diambil untuk mengantisipasinya. Dari ketiga indikator yaitu mutu, biaya, dan waktu, diperoleh nilai risiko tertinggi berkisar 8-14. Hal ini menunjukan risiko tersebut adalah sedang (medium risk).
3.1 Analisa Penyebab, Dampak Dan Tindakan Preventif Analisa ini dilakukan untuk mencari tahu akar permasalahan dari terjadinya risiko tersebut yang berdampak terhadap mutu, biaya, dan waktu. Diharapkan dari pemetaan penyebab dari berbagai risiko tersebut akan didapatkan solusi dalam pencegahan secara tepat untuk meminimalkan risiko dalam pekerjaan konstruksi. Analisa penyebab, dampak, dan tindakan preventif dari risiko dominan dari penelitian ini dapat dilihat pada Tabel 4 .

Suatu pedoman preventif dapat bermanfaat untuk membantu penyedia jasa dalam menangani risiko yang terjadi dalam pelaksanaan proyek konstruksi. Pedoman preventif juga bermanfaat untuk membantu penyedia jasa mencegah klaim berkembang menjadi dispute. Pedoman preventif dapat disusun dengan tahapan melakukan identifikasi potensi-potensi risiko yang mungkin terjadi, menentukan penyebab dari masing-masing potensi risiko tersebut berdasarkan pengalaman terdahulu, lalu membuat daftar tindakan preventif yang dapat dilakukan untuk mengurangi atau mengeliminasi penyebabpenyebab dari klaim tersebut.

Berdasarkan matriks analisis deskriptif pada Tabel 3, semua penyebab dan dampak dari risiko terpetakan pada risiko dominan. Dalam penelitian ini, faktor risko dominan yang diambil hanya dua variabel yang memperoleh nilai mean tertinggi yaitu variabel X13 "tidak menghitung mutual check nol dengan akurat saat hendak melakukan pekerjaan" dan variabel X1 "tidak segera memperbaiki kecatatan pada material”. Dari kedua variabel ini akan berpengaruh terhadap risiko proyek konstruksi gedung. Faktor penyebab, dampak dan

Tabel 4 Analisa Penyebab, Dampak, dan Tindakan Preventif

\begin{tabular}{cc}
\hline Kode & Penyebab \\
\hline P1 & Konsultan pengawas lapangan yang kurang baik terhadap pemeriksaan mutu material dilapangan \\
P2 & Kecerobohan kontraktor dalam membelajakan material, sehingga membuat realcost kontraktor meningkat \\
P3 & Pemilihan tenaga Teknis yang tidak tepat baik kualitas maupun kuantitasnya. \\
P4 & Tidak adanya satu unit sistem informasi manajemen untuk memantau dan menganalisa apa yang terjadi dan tindakan apa \\
P5 & yang perlu diambil untuk mengantisipasinya \\
P6 & Penyusunan rangkaian pekerjaan yang kurang baik \\
P7 & Kurangnya waktu yang diberikan owner dalam membuat MC 0 \\
P8 & Lemahnya pengawasan kontraktor di lapangan \\
P9 & Kurangnya pengalaman dan kompetensi dari pekerja \\
P10 & Cuaca buruk \\
P11 & Peralatan konstruksi yang tidak sesuai \\
Kode & Penggunaan material yang tidak sesuai dengan spesifikasi \\
\hline D1 & Berpengaruh terhadap pekerjaan yang nantinya akan di aksanakan apakah mengalami perubahan, bertambah / berkurang / \\
D2 & tetap volume. \\
D3 & Pekerjaan rework (mengulang) untuk memperbaiki hasil pekerjaan yang sudah dikerjakan \\
\hline Kode & Berpengaruh terhadap risiko mutu, biaya, dan waktu pada proyek \\
\hline TP1 & Sebelum Pekerjaan dimulai kontraktor wajib melakukan Mutual Check Nol supaya potensi kekurangan / kelebihan volume \\
TP2 & Sebelum membelanjakan material kontraktor harus terlebih dahulu mengecek terkait dengan dimensi serta mutu yang akan \\
TP3 & dibeli agar sesuai dengan spesifikasi dan gambar kerja \\
TP4 & Kontraktor membuat satu unit sistem informasi manajemen untuk memantau dan menganalisa apa yang terjadi dan \\
TP5 & tindakan apa yang perlu diambil untuk mengantisipasinya \\
TP6 & Merekkrut tenaga teknik yang berkualitas \\
TP7 & Memperketat pengawasan oleh staf kontraktor/konsultan dilapangan \\
TP8 & Membuat training (pelatihan) khusus bagi pekerja \\
\hline
\end{tabular}


tindakan preventif dari risiko dominan utama yaitu variabel X13 dapat dilihat pada Gambar 1 .

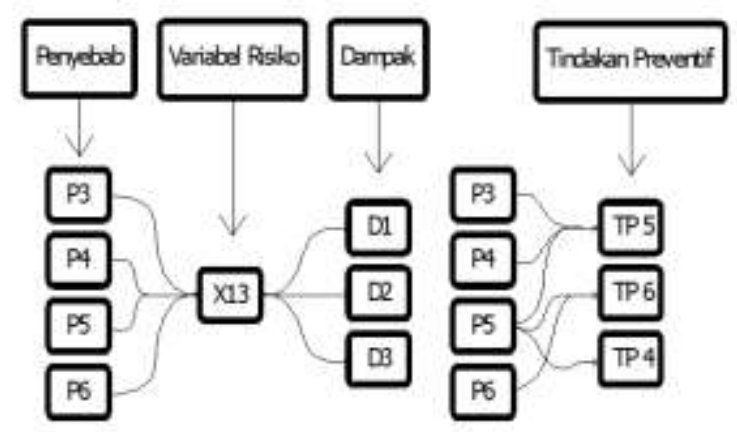

Gambar 1. Analisa penyebab, dampak, tindakan preventif dari risiko variabel X13

Dalam variabel risiko utama atau dominan X13 yaitu "Tidak menghitung mutual check 0 dengan akurat saat hendak melakukan pekerjaan”. Hal ini dikarenakan waktu yang disediakan oleh owner kepada kontraktor untuk menghitung mutual check 0 terlalu sedikit sehingga kontraktor tidak cukup waktu untuk menyelesaikannya dengan baik. Penyebab lain karena kurangnya tenaga teknik yang berkompeten di bidang manajemen estimasi biaya sehingga dalam menghitung volume pekerjaan masih ada kekeliruan sehingga akan ada amandemen yang berulang. Hal ini akan berdampak pada keterlambatan waktu penyelesaian proyek itu sendiri, sehingga akan berpengaruh pada tambahan biaya dimana jumlahnya lebih besar dibandingkan jumlah biaya yang diestimasikan pada awal proyek. Tindakan pencegahan yang dapat dilakukan dari risiko tersebut adalah dengan mencari sumber daya manusia yang berkualitas dan kontraktor memastikan sebelum hendak melaksanakan pekerjaan kontraktor wajib melakukan mutual check nol dengan tepat supaya potensi kekurangan/kelebihan volume dapat dihindarkan.

Faktor penyebab, dampak dan tindakan preventif dari risiko dominan kedua yaitu variabel X1 yaitu "tidak segera memperbaiki kecatatan pada material" sebagaimana ditunjukkan pada Gambar 2. Variabel risiko dominan kedua yaitu X1, "tidak segera memperbaiki kecatatan pada material”. Hal ini disebabkan lemahnya pengawasan oleh staf kontraktor/konsultan, kurangnya pengalaman dan kompetensi dari pekerja, cuaca buruk, peralatan konstruksi yang tidak sesuai, dan penggunaan material yang tidak sesuai dengan spesifikasi. Dampaknya adalah adanya pengerjaan ulang (rework) yang menyebabkan semakin besarnya biaya, tenaga, dan waktu yang harus dikeluarkan oleh perusahaan konstruksi untuk mengerjakan ulang produk yang tidak lolos inspeksi. Tindakan preventif (pencegahan) yang cukup efektif untuk dapat dilakukan dari risiko tersebut yaitu dengan memperketat pengawasan di lapangan oleh staf kontraktor dan konsultan. Kontraktor sebelum membelanjakan material harus terlebih dahulu mengecek dimensi serta mutu yang akan dibeli agar sesuai dengan spesifikasi dan gambar kerja yang diminta owner, membuat training (pelatihan) bagi pekerja serta pengelolaan manajemen yang baik.

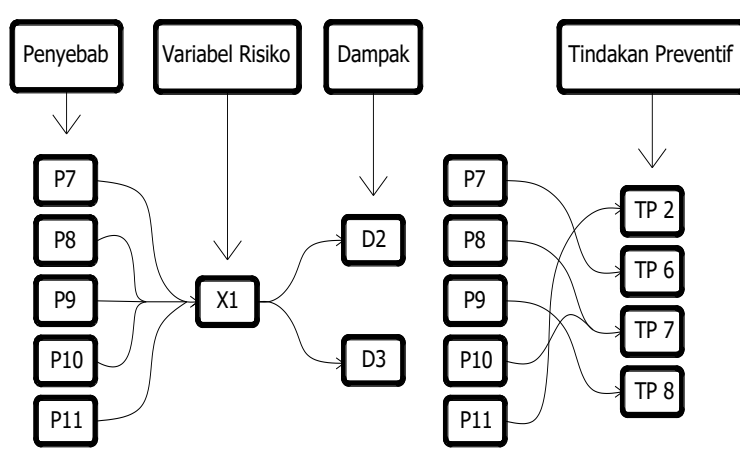

Gambar 2. Analisa penyebab, dampak, tindakan preventif dari risiko variabel X1

\section{KESIMPULAN}

Berdasarkan analisis risiko dengan menggunakan probability impact matriks, diketahui bahwa dua risiko tertinggi yaitu variabel X13 “tidak menghitung mutual check nol dengan akurat saat hendak melakukan pekerjaan" serta variabel X1 "tidak segera memperbaiki kecatatan pada material”. Dari risiko tersebut, perlu tindakan preventif supaya risiko tersebut dapat dihindari. Suatu pedoman preventif dapat bermanfaat untuk membantu penyedia jasa dalam menangani risiko yang terjadi dalam pelaksanaan proyek konstruksi serta membantu penyedia jasa mencegah klaim berkembang menjadi dispute. Tindakan pencegahan yang dapat dilakukan dari risiko tersebut adalah dengan mencari sumber daya manusia yang berkualitas, memperketat pengawasan di lapangan, membuat pelatihan bagi pekerja serta pengelolaan manajemen yang baik.

\section{Daftar Pustaka}

Dita, A. O., Ratnaningsih, A., \& Sukmawati, S. (2017). Identifikasi Risiko Dominan Internal Non Teknis Yang Berdampak Pada Biaya Konstruksi High Rise Building Menggunakan Metode Severity Index. Jurnal Teoritis dan Terapan Bidang Rekayasa Ketekniksipilan dan Lingkungan, 1(2), 178-191.

Loosemore, M., Raftery, J., Reilly, C., \& Higgon, D. (2006). Risk management in projects. London: Taylor \& Francis.

Project Management Institute. (2013). A Guide to the Project Management Body of Knowledge. Atlanta: The Project Management Institute, Inc. (PMI).

Ratnaningsih, A., Dokhikah, Y., \& Fitria, A. (2018). Hazard identification, risk analysis and risk assessment on high-rise building construction project. HumanDedicated Sustainable Product and Process Design: Materials, Resources, and Energy (p. 020014). AIP.

Sufa'atin. (2017). mplementasi Probability Impact Matriks (PIM) Untuk Mengidentifikasi Kemungkinan dan Dampak Risiko Proyek. Jurnal ULTIMA InfoSys, 8(1), 43-47.

Sun, Y., Fang, D., \& Wang, S. Q. (2008). Safety Risk Identification and Assessment for Beijing Olympic Venues Construction. Journal of Management in Engineering, 24(1), 40-47.

Zhang, S., Zhang, S., Gong, Y., \& Ding, X. (2016). Contractual Governance: Effects of Risk Allocation on Contractors' Cooperative Behavior in Construction Projects. Journal of Construction Engineering and Management, 142(6). 
Hayati, Fatimah, \& Akmal/ Buletin Teknik Sipil 1:2 (2021) 81-86 